\title{
Right Lateral Decubitus Position
}

National Cancer Institute

\section{Source}

National Cancer Institute. Right Lateral Decubitus Position. NCI Thesaurus. Code C62171.

Lying down or reclining with the right side in a downward direction. 